\title{
Checkmite!? Is the Resistance to Phytophagous Mites on Short and Stocky Wild Oryza Species?
}

\author{
Raul A. Sperotto ${ }^{1,2 *}$, Giseli Buffon ${ }^{1}$, Joséli Schwambach ${ }^{3}$ and Felipe K. Ricachenevsky ${ }^{4,5}$ \\ ${ }^{1}$ Graduate Program in Biotechnology, University of Taquari Valley, Univates, Lajeado, Brazil, ${ }^{2}$ Biological Sciences and Health \\ Center, University of Taquari Valley, Univates, Lajeado, Brazil, ${ }^{3}$ Graduate Program in Biotechnology, University of Caxias do \\ Sul, Caxias do Sul, Brazil, ${ }^{4}$ Graduate Program in Agrobiology, Federal University of Santa Maria, Santa Maria, Brazil, \\ ${ }^{5}$ Graduate Program in Cell and Molecular Biology, Federal University of Rio Grande do Sul, Porto Alegre, Brazil
}

Keywords: gibberellin, jasmonate, mite resistance, plant defense, wild species

Plants must effectively defend against environmental stresses to survive in nature. However, immunity to disease is costly and often comes with a significant growth inhibition and yield penalty (Yang et al., 2012; Huot et al., 2014; Huang et al., 2017; Ning et al., 2017). Hormones play important roles in regulating plant growth and stress responses (Heinrich et al., 2013). Gibberellins (GAs) and jasmonates (JAs) are two types of essential phytohormones that control many aspects of plant growth and development in response to environmental and endogenous signals. GA regulates many essential plant developmental processes (including stem and leaf elongation), while JA plays a dominant role in mediating plant defense, especially to herbivores attack (Hou et al., 2013). Even though GA and JA antagonize each other in regulating plant growth and defense response via interaction between JAZs and DELLAs proteins (De Bruyne et al., 2014; Song et al., 2014;

OPEN ACCESS

Edited by:

Victor Flors,

Jaume I University, Spain

Reviewed by:

Mónica Asunción Hurtado Ruiz, Jaume I University, Spain

*Correspondence:

Raul A. Sperotto

rasperotto@univates.br

Specialty section: This article was submitted to

Plant Microbe Interactions, a section of the journal

Frontiers in Plant Science

Received: 02 January 2018 Accepted: 27 February 2018

Published: 13 March 2018

Citation:

Sperotto RA, Buffon G,

Schwambach $J$ and

Ricachenevsky FK (2018) Checkmite!? Is the Resistance to Phytophagous Mites on Short and Stocky Wild Oryza

Species? Front. Plant Sci. 9:321. doi: 10.3389/fp/s.2018.00321
Chaiwanon et al., 2016), the exactly way how plants coordinate the fluctuating growth-defense dynamics is not well understood. Especially, the role of GA in growth-defense conflicts during herbivory is yet to be characterized. Several works have been addressing the plant dilemma between "to grow" and "to defend" in response to various stimuli, clearly indicating that plants need to prioritize GA- or JA-induced responses. Heinrich et al. (2013) showed that high levels of JA antagonize the biosynthesis of GA and inhibit the growth of Nicotiana attenuata stems. In rice, GA application was found to decrease resistance to the hemibiotrophic rice pathogens Magnaporthe oryzae (Mo) and Xanthomonas oryzae pv. oryzae (Xoo) (Yang et al., 2008; Qin et al., 2013). The GA biosynthetic pathway and signaling cascade were shown to be regulated by JA during Mo and Xoo interactions with rice plants. It was also shown that the only DELLA protein in rice, SLR1, is crucial to integrate GA and JA (as well as salicylic acid) crosstalk (De Vleesschauwer et al., 2016). In agreement with that, rice plants overexpressing a GA deactivating enzyme accumulated low levels of GA and displayed enhanced resistance to Mo and Xoo, whereas plants harboring loss-of-function mutations in the same gene were more vulnerable to these pathogens (Yang et al., 2008; De Bruyne et al., 2014).

Upon attack by the chewing herbivore Chilo suppressalis, rice plants activate the expression of OsWRKY70, a transcription factor that physically interacts with W-box motifs and prioritizes defense over growth by positively regulating JA and negatively regulating GA biosynthesis ( $\mathrm{Li}$ et al., 2015). Two groups investigated the growth/defense response of rice plants infested by brown planthopper (BPH) insect: (1) Wang et al. (2015) detected a shift from growth to defense in response to BPH infestation, evidenced by downregulation of GA-related genes, decreased GA levels, increased JA levels, and reduced plant growth; (2) Qi et al. (2016) showed that plants over-expressing OsJMT1 (JA carboxyl methyltransferase, which is up-regulated by BPH infestation and is a key enzyme in methyl-JA biosynthesis pathway) exhibited increased MeJA levels and reduced height. In line with these findings, we previously detected lower expression of three GA biosynthetic 
pathway-related genes (OsGA2ox1, OsGA2ox3, and OsGA20ox1) in rice leaves infested with the phytophagous mite Schizotetranychus oryzae, when compared with control leaves. The expression of OsAOS (allene oxide synthase), which catalyzes the committed step in JA biosynthesis, was only detected in infested leaves (Buffon et al, 2016). Altogether, these results suggest that JA-related responses antagonize the biosynthesis of GA and GA-related responses during herbivory.

Wild plant species have been widely recognized as valuable source of resistance genes for developing herbivore-resistant cultivars. For example, Oryza brachyantha is resistant to the rice leaf folder Cnaphalocrocis medinalis (Ramachandran and Khan, 1991; Ricachenevsky et al., 2018). To date, 10 QTLs and one causative gene have been identified from six wild rice species (O. officinalis, O. eichingeri, O. minuta, O. latifolia, O. rufipogon, and O. australiensis-Huang et al., 2013; Zhang et al., 2014; $\mathrm{Hu}$ et al., 2015; Ji et al., 2016). With this in mind, we asked ourselves whether wild rice cultivars could also present some degree of resistance to Schizotetranychus oryzae mite infestation. Surprisingly, the wild rice genotypes tested (O. glaberrima and $O$. barthii) were characterized as highly sensitive to $S$. oryzae infestation, being even more sensitive than cultivated $O$. sativa genotypes (Figures 1A,B). Similar results were reported by Veasey et al. (2008), which tested the infestation of S. oryzae in four wild rice species (O. glumaepatula, O. latifolia, O. alta, and O. grandiglumis), and Chandrasena et al. (2016), which tested the infestation of panicle rice mite Steneotarsonemus spinki in five wild rice species (O. nivara, O. eichingeri, O. rufipogon, O. granulata, and O. rhizomatis), with no signs of mite resistance.

Taking into account the antagonism between JA and GA, and that breeding of cultivated rice during the Green Revolution has selected for low GA/GA-insensitive genotypes, as shown by the semi-dwarf phenotype of modern rice cultivars (Spielmeyer et al., 2002), we believe the mite-sensitivity presented by the wild rice species could be explained, at least partially, by a presumable high GA:JA ratio in these plants. Tested wild species are tall plants, varying from 1.5 to $5 \mathrm{~m}$, and probably have high levels of GA synthesis. It is important to highlight that a plant's height is not only dependent on the GA level, and resistance to herbivores is not only dependent on the JA level. However, considering the high variability found on the genomes of wild rice species and the high number of already identified insect-resistance genes, we hypothesize that a short (or a semi-dwarf) wild rice species could present a significant level of mite-resistance. In line with our assumption, the semi-dwarf IR36 rice cultivar (one of many of the Green Revolution which replaced many local strains and genetic diversity previously found in rice paddies, resulted from a cross-breeding of IR8 with 13 parent varieties from six nations and a wild species of rice, O. nivara) is resistant to many pests and diseases, including green leafhopper (Nephotettix virescens), $\mathrm{BPH}$, stem borer (Chilo sp.), blast blight (Pyricularia oryzae), bacterial blight (Xanthomonas campestris pv oryzae), tungro, and grassy stunt viruses (Innes, 1992).

Therefore, we would like to suggest short Oryza species and genotypes as primary sources of herbivory tolerance, including mites. We should expect low GA levels/sensitivity, and therefore high SLR1 (the sole DELLA protein in rice) levels in these plants. Accumulated SLR1 will amplify the JA-response, driving plant resources toward defense instead of growth (Chaiwanon et al., 2016; De Vleesschauwer et al., 2016). Obviously, we do not expect the GA-JA switch to be the sole determinant of resistance. However, plants with high GA stimulus are more likely to have lower levels of SLR1, freeing JAZ proteins to sequester JA-response activation transcription factors and in turn attenuate JA-mediated resistance (Figure 1C). Thus, we should focus our efforts in searching for useful genes in genotypes that are already primed to JA defense responses (i.e., plants with low GA level/sensitivity and therefore high SLR1 levels, which would amplify JA-responses and drive plant resources toward defense instead of growth).

We suggest O. minuta, O. meyeriana, O. neocaledonica, and O. schlechteri (http://www.knowledgebank.irri.org/images/ docs/wild-rice-taxonomy.pdf) as possible sources of miteresistance genes. O. minuta $(2 n=48$, BBCC genome, $1 \mathrm{~m}$ tall, perennial) exhibits significant potential to resist to several pests/diseases (http://archive.gramene.org/species/ oryza_species/o_minuta.html), including blast blight, bacterial blight (BB), white-backed planthopper (WBPH), and brown planthopper (BPH) (Amante-Bordeos et al., 1992; You et al., 2007; Rahman et al., 2009; Asaf et al., 2016, 2017), which are damaging to the growth and yield of cultivated rice. Few studies have been conducted to identify and transfer the resistance genes from O. minuta to cultivated rice (Amante-Bordeos et al., 1992; Rahman et al., 2009). However, no hybrid with commercial rice cultivar with elevated resistance to herbivores have been developed so far. O. meyeriana $(2 n=24$, GG genome, about $50 \mathrm{~cm}$ tall, perennial) is adapted to survive in harsh environments and possesses many useful traits absent in cultivated rice, including high resistance to rice blast and bacterial blight, which has been transferred to cultivated rice (O. sativa) (Yan et al., 2004; Han et al., 2014; He et al., 2015; Chen et al., 2016; Cheng et al., 2016). O. neocaledonica ( $2 n=24$, GG genome, $60-80 \mathrm{~cm}$ tall, perennial), is the latest species described in the genus Oryza (Nayar, 2014). First considered a subspecies/variety/population of O. meyeriana (Vaughan, 2003), it was later recognized as a valid Oryza species (Clayton et al., 2010 - https://www.kew. org/data/grasses-db.html). Surprisingly, no studies are known to have been done on O. neocaledonica (Nayar, 2014), evidencing an unexplored gene diversity. O. schlechteri $(2 n=48$, HНKK genome, $30-90 \mathrm{~cm}$ tall, annual), found in undisturbed forests, is the least studied species in the genus (Brar and Singh, 2011). Based on bioclimatic analysis, Atwell et al. (2014) pointed O. schlechteri as a candidate species for flooding tolerance. Regarding biotic stress response, no studies have been done with this species, and for this reason is an irreplaceable material for improving the cultivated varieties.

Even though herbivore resistance is commonly a genetically determined trait that shows heritable genetic variation (Muola et al., 2010), it is important to highlight that before including a plant material as a primary source in a breeding program, is essential to know the heritability of the trait and how stable the trait would be when transmitted to the offspring. Therefore, it would be interesting to examine whether and how environmental factors regulate GA:JA ratio/crosstalk and mite resistance in 
A

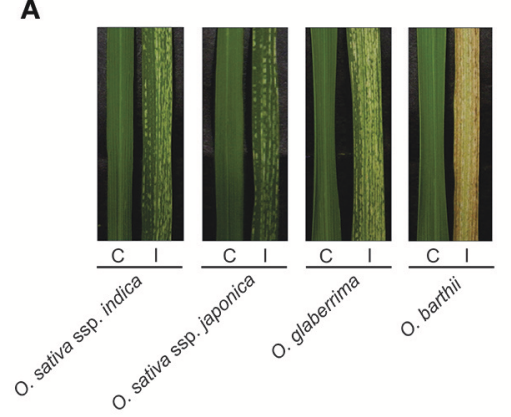

B

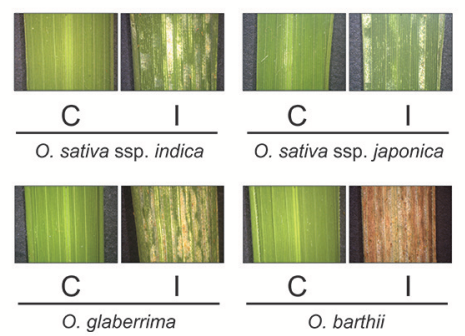

C

Short resistant plants

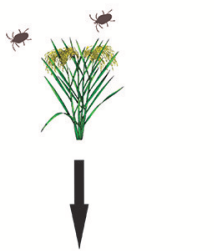

Low GA level/sensitivity

High SLR1 expression

Amplified JA response

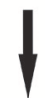

Expression of resistance genes Prioritize defense over growth Reduced plant growth
Tall susceptible plants

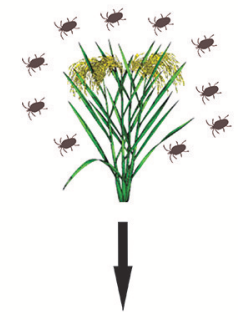

High GA level/sensitivity

Low SLR1 expression

Low JA response

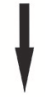

Repression of resistance genes

Prioritize growth over defense

Sustained plant growth

FIGURE 1 | Visual characteristics of leaves from O. sativa ssp. indica, O. sativa ssp. japonica, O. glaberrima, and O. barthii plants, under control (C) and infested (I) conditions (A). Detailed view of these leaves under stereomicroscope (B). Schematic model of the different responses probably employed by short resistant and tall susceptible plants (C).

these short and stocky wild rice species. Also, we are aware that crossing often fails to generate fertile hybrids between cultivated rice and wild species because of reproductive barriers (Han et al., 2014). However, the use of asymmetric somatic hybridization has proved to be effective (Jena, 2010). Therefore, searching for mite resistance genes taking GA-JA crosstalk into account, together with comprehensive screens in the wild rice diversity, should be

\section{REFERENCES}

Amante-Bordeos, A., Sitch, L. A., Nelson, R., Dalmacio, R. D., Oliva, N. P., Aswidinnoor, H., et al. (1992). Transfer of bacterial blight and blast resistance from the tetraploid wild rice Oryza minuta to cultivated rice, Oryza sativa. Theor. Appl. Genet. 84, 345-354. doi: 10.1007/BF00229493

Asaf, S., Khan, A. L., Khan, A. R., Waqas, M., Kang, S. M., Khan, M. A., et al. (2016). Mitochondrial genome analysis of wild rice (Oryza minuta) and its comparison with other related species. PLoS ONE 11:e0152937. doi: 10.1371/journal.pone.0152937

Asaf, S., Waqas, M., Khan, A. L., Khan, M. A., Kang, S. M., Imran, Q. M., et al. (2017). The complete chloroplast genome of wild rice (Oryza minuta) and its comparison to related species. Front. Plant Sci. 8:304. doi: $10.3389 /$ fpls.2017.00304

Atwell, B. J., Wang, H., and Scafaro, A. P. (2014). Could abiotic stress tolerance in wild relatives of rice be used to improve Oryza sativa? Plant Sci. 215-216, 48-58. doi: 10.1016/j.plantsci.2013.10.007

Brar, D. S., and Singh, K. (2011). "Oryza," in Wild Crop Relatives: Genomic and Breeding Resources - Cereals, ed C. Kole (Berlin; Heidelberg: SpringerVerlag), 321-365. Available online at: http://www.springer.com/br/book/ 9783642142277

Buffon, G., Blasi, É. A., Adamski, J. M., Ferla, N. J., Berger, M., Santi, L., et al. (2016). Physiological and molecular alterations promoted by Schizotetranychus oryzae mite infestation in rice leaves. J. Prot. Res. 15. 431-446. doi: 10.1021/acs.jproteome.5b00729 fruitful to develop mite resistance in susceptible cultivated rice lines.

\section{AUTHOR CONTRIBUTIONS}

All authors listed have made a substantial, direct and intellectual contribution to the work, and approved it for publication.

Chaiwanon, J., Wang, W., Zhu, J. Y., Oh, E., and Wang, Z. Y. (2016). Information integration and communication in plant growth regulation. Cell 164, 1257-1268. doi: 10.1016/j.cell.2016.01.044

Chandrasena, G. D. S. N., Jayawardane, J. D. K. M., Umange, S. D., and Gunawardana, A. D. B. U. (2016). Host range of panicle rice mite Steneotarsonemus spinki smiley (Acari: Tarsonemidae) in Sri Lanka. Univ. J. Agric. Res. 4, 21-24. doi: 10.13189/ujar.2016.040104

Chen, X., Dong, Y., Yu, C., Fang, X., Deng, Z., Yan, C., et al. (2016). Analysis of the proteins secreted from the Oryza meyeriana suspension-cultured cells induced by Xanthomonas oryzae pv. oryzae. PLoS ONE 11:e0154793. doi: 10.1371/journal.pone.0154793

Cheng, X. J., He, B., Chen, L., Xiao, S. Q., Fu, J., Chen, Y., et al. (2016). Transcriptome analysis confers a complex disease resistance network in wild rice Oryza meyeriana against Xanthomonas oryzae pv. oryzae. Sci. Rep. 6:38215. doi: $10.1038 /$ srep38215

Clayton, W. D., Vorontsova, M. S., Harman, K. T., and Williamson, H. (2010). GrassBase - the Online World Grass Flora. Available online at: https://www.kew. org/data/grasses-db.html

De Bruyne, L., Höfte, M., and De Vleesschauwer, D. (2014). Connecting growth and defense: the emerging roles of brassinosteroids and gibberellins in plant innate immunity. Mol. Plant 7, 943-959. doi: 10.1093/mp/ssu050

De Vleesschauwer, D., Seifi, H. S., Filipe, O., Haeck, A., Huu, S. N., Demeestere, K., et al. (2016). The DELLA protein SLR1 integrates and amplifies salicylic acid- and jasmonic acid-dependent innate immunity in rice. Plant Physiol. 170, 1831-1847. doi: 10.1104/pp.15.01515 
Han, X., Yang, Y., Wang, X., Zhou, J., Zhang, W., Yu, C., et al. (2014). Quantitative trait loci mapping for bacterial blight resistance in rice using bulked segregant analysis. Int. J. Mol. Sci. 15, 11847-11861. doi: 10.3390/ijms150711847

He, B., Tao, X., Gu, Y., Wei, C., Cheng, X., Xiao, S., et al. (2015). Transcriptomic analysis and the expression of disease-resistant genes in Oryza meyeriana under native condition. PLoS ONE 10:e0144518. doi: 10.1371/journal.pone.0144518

Heinrich, M., Hettenhausen, C., Lange, T., Wünsche, H., Fang, J., Baldwin, I. T., et al. (2013). High levels of jasmonic acid antagonize the biosynthesis of gibberellins and inhibit the growth of Nicotiana attenuata stems. Plant J. 73, 591-606. doi: 10.1111/tpj.12058

Hou, X., Ding, L., and Yu, H. (2013). Crosstalk between GA and JA signaling mediates plant growth and defense. Plant Cell Rep. 32, 1067-1074. doi: 10.1007/s00299-013-1423-4

Hu, J., Xiao, C., Cheng, M. X., Gao, G. J., Zhang, Q. L., and He, Y. Q. (2015). A new finely mapped Oryza australiensis-derived QTL in rice confers resistance to brown planthopper. Gene 561, 132-137. doi: 10.1016/j.gene.2015.02.026

Huang, D., Qiu, Y., Zhang, Y., Huang, F., Meng, J., Wei, S., et al. (2013). Fine mapping and characterization of $\mathrm{BPH} 27$, a brown planthopper resistance gene from wild rice (Oryza rufipogon Griff.). Theor. Appl. Genet. 126, 219-229. doi: 10.1007/s00122-012-1975-7

Huang, H., Liu, B., Liu, L., and Song, S. (2017). Jasmonate action in plant growth and development. J. Exp. Bot. 68, 1349-1359. doi: 10.1093/jxb/erw495

Huot, B., Yao, J., Montgomery, B. L., and He, S. Y. (2014). Growth-defense tradeoffs in plants: a balancing act to optimize fitness. Mol. Plant 7, 1267-1287. doi: $10.1093 / \mathrm{mp} / \mathrm{ssu} 049$

Innes, N. L. (1992). Gene banks and their contribution to the breeding of disease resistant cultivars. Euphytica 63, 23-31. doi: 10.1007/BF00023909

Jena, K. K. (2010). The species of the genus Oryza and transfer of useful genes from wild species into cultivated rice, O. sativa. Breed. Sci. 60, 518-523. doi: $10.1270 /$ jsbbs. 60.518

Ji, H., Kim, S. R., Kim, Y. H., Suh, J. P., Park, H. M., Sreenivasulu, N., et al. (2016). Map-based cloning and characterization of the BPH18 gene from wild rice conferring resistance to Brown Planthopper (BPH) insect pest. Sci. Rep. 6:34376. doi: 10.1038/srep34376

Li, R., Zhang, J., Li, J., Zhou, G., Wang, Q., Bian, W., et al. (2015). Prioritizing plant defence over growth through WRKY regulation facilitates infestation by non-target herbivores. eLife 4:e04805. doi: 10.7554/eLife.04805

Muola, A., Mutikainen, P., Laukkanen, L., Lilley, M., and Leimu, R. (2010). Genetic variation in herbivore resistance and tolerance: the role of plant life-history stage and type of damage. J. Evol. Biol. 23, 2185-2196. doi: 10.1111/j.1420-9101.2010.02077.x

Nayar, N. M. (2014). "Oryza species and their interrelationships," in Origin and Phylogeny of Rices, ed N. M. Nayar (Oxford, UK: Elsevier Academic Press), 59-115.

Ning, Y., Liu, W., and Wang, G. L. (2017). Balancing immunity and yield in crop plants. Trends Plant Sci. 22, 1069-1079. doi: 10.1016/j.tplants.2017.09.010

Qi, J., Li, J., Han, X., Li, R., Wu, J., Yu, H., et al. (2016). Jasmonic acid carboxyl methyltransferase regulates development and herbivory-induced defense response in rice. J. Int. Plant Biol. 58, 564-576. doi: 10.1111/jipb.12436

Qin, X., Liu, J. H., Zhao, W. S., Chen, X. J., Guo, Z. J., and Peng, Y. L. (2013). Gibberellin 20-oxidase gene OsGA20ox3 regulates plant stature and disease development in rice. Mol. Plant Microbe Interact. 26, 227-239. doi: 10.1094/MPMI-05-12-0138-R

Rahman, M. L., Jiang, W., Chu, S. H., Qiao, Y., Ham, T. H., Woo, M. O., et al. (2009). High-resolution mapping of two rice brown planthopper resistancegenes, Bph20(t) and Bph21(t), originating from Oryza minuta. Theor.
Appl. Genet. 119, 1237-1246. doi: 10.1007/s00122-009-1125-Z

Ramachandran, R., and Khan, Z. R. (1991). Mechanisms of resistance in wild rice Oryza brachyantha to rice leaf folder Cnaphalocrocis medinalis (Guenée) (Lepidoptera: Pyralidae). J. Chem. Ecol. 17, 41-65. doi: 10.1007/BF00994421

Ricachenevsky, F. K., Buffon, G., Schwambach, J. and Sperotto, R. A. (2018). "Oryza brachyantha A. Chev. et Roehr," in The Wild Oryza Genomes. Compendium of Plant Genomes, eds T. Mondal and R. Henry (Cham: Springer), 75-85. doi: 10.1007/978-3-319-71997-9_7

Song, S., Qi, T., Wasternack, C., and Xie, D. (2014). Jasmonate signaling and crosstalk with gibberellin and ethylene. Curr. Opin. Plant Biol. 21, 112-119. doi: 10.1016/j.pbi.2014.07.005

Spielmeyer, W., Ellis, M. H., and Chandler, P. M. (2002). Semidwarf (sd-1), "green revolution" rice, contains a defective gibberellin 20-oxidase gene. Proc. Natl. Acad. Sci. U.S.A. 99, 9043-9048. doi: 10.1073/pnas.132266399

Vaughan, D. A. (2003). "Genepools of the genus Oryza”, in Monograph on Genus Oryza, eds J. S. Nanda and S. D. Sharma (Enfield, NH: Science Publishers), 113-138.

Veasey, E. A., da Silva, E. F., Schammass, E. A., Oliveira, G. C. X., and Ando, A. (2008). Morphoagronomic genetic diversity in american wild rice species. Braz. Arch. Biol. Technol. 51, 95-104. doi: 10.1590/S1516-891320080 00100012

Wang, F., Ning, D., Chen, Y., Dang, C., Han, N. S., Liu, Y., et al. (2015). Comparing gene expression profiles between $\mathrm{Bt}$ and non-Bt rice in response to brown planthopper infestation. Front. Plant Sci. 6:1181. doi: 10.3389/fpls.2015.01181

Yan, C. Q., Qian, K. X., Yan, Q. S., Zhang, X. Q., Xue, G. P., Huangfu, W. G., et al. (2004). Use of asymmetric somatic hybridization for transfer of the bacterial resistance trait from Oryza meyeriana L. to O. sativa L. ssp. japonica. Plant Cell Rep. 22, 569-575. doi: 10.1007/s00299-003-0732-4

Yang, D. L., Li, Q., Deng, Y. W., Lou, Y. G., Wang, M. Y., Zhou, G. X., et al. (2008). Altered disease development in the Eui mutants and Eui overexpressors indicates that gibberellins negatively regulate rice basal disease resistance. Mol. Plant 1, 528-537. doi: 10.1093/mp/ssn021

Yang, D. L., Yao, J., Mei, C. S., Tong, X. H., Zeng, L. J., Li, Q., et al. (2012). Plant hormone jasmonate prioritizes defense over growth by interfering with gibberellin signaling cascade. Proc. Nat. Acad. Sci. U.S.A. 109, 1192-1200. doi: 10.1073/pnas.1201616109

You, M. K., Oh, S. I., Ok, S. H., Cho, S. K., Shin, H. Y., Jeung, J. U., et al. (2007). Identification of putative MAPK kinases in Oryza minuta and O. sativa responsive to biotic stresses. Mol. Cells 23, 108-114.

Zhang, W., Dong, Y., Yang, L., Ma, B., Ma, R., Huang, F., et al. (2014). Small brown planthopper resistance loci in wild rice (Oryza officinalis). Mol. Genet. Genomics 289, 373-382. doi: 10.1007/s00438-014-0814-8

Conflict of Interest Statement: The authors declare that the research was conducted in the absence of any commercial or financial relationships that could be construed as a potential conflict of interest.

The reviewer MAHR and handling Editor declared their shared affiliation.

Copyright (C) 2018 Sperotto, Buffon, Schwambach and Ricachenevsky. This is an open-access article distributed under the terms of the Creative Commons Attribution License (CC BY). The use, distribution or reproduction in other forums is permitted, provided the original author(s) and the copyright owner are credited and that the original publication in this journal is cited, in accordance with accepted academic practice. No use, distribution or reproduction is permitted which does not comply with these terms. 